\title{
Characterizing the Health-Related Quality of Life Burden of Overactive Bladder Using Disease-Specific Patient-Reported Outcome Measures: A Systematic Literature Review
}

\author{
Karissa M. Johnston · David R. Walker • Pardis Lakzadeh
}

Received: November 30, 2018 / Published online: February 4, 2019

(C) The Author(s) 2019

\begin{abstract}
Introduction: The objective was to identify the most commonly used patient-reported outcome (PRO) instruments for overactive bladder $(\mathrm{OAB})$, determine which are the most useful for measuring burden in $\mathrm{OAB}$ and characterize the findings of recent studies that have employed PRO instruments to assess OAB symptoms and the effects of treatment.

Methods: A systematic search of OAB literature published between January 2006 and November 2017 using Medline/PubMed and EMBASE databases.

Results: Of 3425 abstracts and 500 full-text articles reviewed, 58 studies (both clinical trials
\end{abstract}

Enhanced Digital Features To view enhanced digital features for this article go to https://doi.org/10.6084/ m9.figshare.7599140.

Electronic supplementary material The online version of this article (https://doi.org/10.1007/s12325019-0880-8) contains supplementary material, which is available to authorized users.

K. M. Johnston $(\bowtie) \cdot$ P. Lakzadeh

Broadstreet Health Economics and Outcomes

Research, Vancouver, BC, Canada

e-mail: kjohnston@broadstreetheor.com

D. R. Walker

Astellas Pharma Global Development, Inc.,

Northbrook, IL, USA and observational studies) were included in the review. The most commonly used PRO instruments were the $\mathrm{OAB}$ Questionnaire (OAB-q; 64\%), followed by the King's Health Questionnaire (KHQ; 31\%) and the Patient Perception of Bladder Condition (PCBC; 21\%). Synthesis of data from studies using the OAB-q showed that $\mathrm{OAB}$ treatment with antimuscarinics, mirabegron and onabotulinumtoxinA all improve health-related quality of life (HRQoL) and symptoms beyond the benefits observed with placebo. The OAB-q could detect dose-response relationships in some studies and demonstrated there were no significant differences across therapies from different drug classes.

Conclusion: The HRQOL burden of OAB and response to treatment can be reliably measured by PRO instruments, and the OAB-q is the most commonly used instrument in $\mathrm{OAB}$, particularly in clinical trials of $\mathrm{OAB}$ interventions. These data will be useful to provide benchmarks of burden levels for PRO scores obtained among those on contemporary therapies for comparison with outcomes from patients managed with emerging treatments.

Funding: Astellas Pharma Global Development, Inc.

Keywords: Overactive bladder; Patient reported outcome; Quality of life; Urinary incontinence; Urology 


\section{INTRODUCTION}

Overactive bladder $(\mathrm{OAB})$ is a chronic debilitating syndrome of the lower urinary tract [1]. The reported prevalence in adults 40 years of age or older is as high as 33\% among women and 16\% among men and increases with age among both sexes [2]. Similar prevalence estimates have been observed across the USA and Europe, with somewhat lower rates reported in Asian countries [3]. Over half of all adults living with $\mathrm{OAB}$ experience bothersome symptoms, which include urinary urgency with or without frequency and incontinence, as well as nocturia, intermittency, slow urine stream, urine strain, incomplete emptying of urine and post-micturition dribble [4]. Urinary frequency is the most commonly reported symptom $[5,6]$ with urge incontinence increasing significantly for women aged over 44 and for men aged over 64 [7]. First-line treatment for OAB typically includes lifestyle and behaviour modifications. Following this, second-line treatments generally involve pharmacotherapy with antimuscarinic or beta-3 adrenergic agonist therapies, such as mirabegron. Subsequent treatment options for patients who fail these interventions include onabotulinumtoxinA, a neurotoxin that is injected into the bladder.

Urinary incontinence, including that due to $\mathrm{OAB}$, has a substantial negative impact on health-related quality of life (HRQoL) and mental health $[4,5,7]$, and interferes with daily activities $[4,8]$. As the impact of OAB symptoms may be difficult to measure directly, efforts to quantify the impact of $\mathrm{OAB}$ symptoms from the patients' perspective have led to the development of a variety of $\mathrm{OAB}$ and urology-specific patient-reported outcome (PRO) instruments. These include the OAB Questionnaire (OAB-q), the King's Health Questionnaire (KHQ), the Patient Perception of Bladder Condition (PPBC) instrument, the Incontinence Impact Questionnaire (IIQ) and the Urinary Distress Inventory (UDI-6). The instruments enable characterization of $\mathrm{OAB}$ symptom control, quantify HRQoL impact and some (e.g. OAB-q, KHQ) permit conversion of scores to a $0-1$ utility scale $[9,10]$ and are commonly used as outcome measures in trials of $\mathrm{OAB}$ treatments. Importantly, validation of a minimal important difference (MID) has made PRO instruments useful tools for identifying clinically significant effects in response to OAB treatment $[11,12]$.

In terms of measure properties, the OAB-q consists of a validated eight-item symptom bother scale used to determine urinary frequency, nocturia, urgency and continence $[13,14]$. It is the first instrument to include an evaluation of both incontinence and continence in $\mathrm{OAB}$ [13], and is therefore widely used because of the ability to generally assess patients with OAB. The OAB-q also includes a 25-item HRQoL scale rating performance in each of four subscales (coping, sleep, concern and social interaction). Each item (including symptom bother items) is scored on a 6-point Likert scale ranging from 1 point (not at all) to 6 points (a very great deal) [13]. A symptom bother total score is derived from the eight-item symptom bother scores, then converted into a 0-100 scale on which higher scores signify greater symptom impact and lower scores signify improved symptom bother [15].

Limited information is available about the frequency of use and sensitivity of PRO instruments, or the consistency of PRO data across clinical trials of OAB interventions. Given how many OAB-specific PROs are available, some criteria to guide measure selection to ensure that results can be compared would be helpful but are presently lacking. To address these knowledge gaps, the aim of this study was to identify the most commonly used instruments in studies of patients with $\mathrm{OAB}$, determine which instruments are the most useful for measuring burden in $\mathrm{OAB}$ and assess the HRQoL implications of $\mathrm{OAB}$ symptoms and the effects of treatment.

\section{METHODS}

\section{Literature Search}

A systematic review of the literature was conducted in Medline/PubMed and EMBASE databases using a customized search strategy (supplementary material Table S1) for literature 
published between January 2006 and November 2017. The search was not limited by country or geographic region; however, it was limited to articles published in English. The design and implementation of the systematic review were guided by the PICOS (Population, Interventions/comparators, Outcomes, Study design) criteria. The population of interest was adults in the USA with $\mathrm{OAB}$, including idiopathic $\mathrm{OAB}$, idiopathic urge urinary incontinence, nonneurogenic urge urinary incontinence or refractory detrusor overactivity, with/without urinary incontinence. Studies were excluded if the population had neurogenic $\mathrm{OAB}$, primarily stress incontinence or a known cause of $\mathrm{OAB}$ such as pregnancy, neoplasm, spinal cord injury or surgery to ensure a more homogenous population was included.

To be included, studies had to present sufficient longitudinal data (either baseline and endof-treatment values, or change scores) to derive change over time using a disease-specific PRO instrument, including the OAB-q (as well as the abbreviated OAB-q short form [SF]); KHQ; PPBC; IIQ-7; UDI-6; Incontinence Specific Quality of Life (i-QOL); Hospital Anxiety Depression Scale (HADS); Overactive Bladder Satisfaction Questionnaire (OAB-S); Patient Perception of Intensity of Urgency Scale (PPIUS); Work Productivity and Activity Impairment (WPAI); and/or the SF; all versions. Observational studies, single-arm trials and randomized controlled trials (RCTs) were all eligible. Studies with a cross-sectional study design, fewer than 100 patients or insufficient information to determine a change in PROs were excluded. Two researchers independently screened abstracts and full-text articles for inclusion or exclusion. Any discrepancies were resolved through a third researcher arbitration.

\section{Assessment of Included Studies}

The reporting standards of the included studies were assessed using the Consolidated Standards of Reporting Trials (CONSORT) criteria for clinical trials [16] and STrengthening the Reporting of OBservational studies in
Epidemiology (STROBE) criteria for observational studies [17].

\section{Data Extraction}

Two researchers extracted data from eligible articles into a customized Microsoft Excel workbook. Study characteristics extracted included authors, country, year, study objective(s), study design, sample size and $\mathrm{OAB}$ treatments. Patient-related data extracted included study level inclusion and exclusion criteria, International Statistical Classification of Diseases, Ninth Revision (ICD-9) codes used to identify $\mathrm{OAB}$ cohorts when relevant and demographic characteristics such as age, sex, comorbidity burden and previous OAB treatment. Outcomes data extracted included mean and standard deviation of all PROs measures of interest at baseline and study end and/or reported change scores over time. Where reported, values of all subdomains were included in addition to overall summary scores. Utility values were extracted where available.

\section{Evidence Synthesis}

The form of data synthesis was driven by the type of data available. Summary tables were generated describing study design, sample size, treatments included, PROs measured and a narrative overview of patient population and results. Results were organized by instrument and then by study type (non-pharmacologic clinical trial, antimuscarinic clinical trial, mirabegron clinical trial, onabotulinumtoxinA clinical trial and observational study).

Criteria to assess the usefulness of available instruments were specified a priori, and developed in line with previously identified recommendations [18]. The following criteria were considered: that the instrument

- Is commonly used in trials of OAB treatments and observational studies

- Comprehensively considers a wide variety of OAB symptoms and bother

- Is specific to $\mathrm{OAB}$, rather than urological conditions more generally

- Has MID data available 
- Can be used to generate a utility value

The properties of the three most frequently used OAB-specific PROs were tabulated and compared. Then, additional assessment and synthesis were performed for the most frequently used instrument, including graphical summary of change scores and comparison of change scores to the established MID.

This article is based on previously conducted studies and does not contain any studies with human participants or animals performed by any of the authors.

\section{RESULTS}

Implementing the search strategy yielded 3425 abstracts, 500 of which underwent full-text review. Fifty-eight studies met the final inclusion criteria, seven of which were identified by

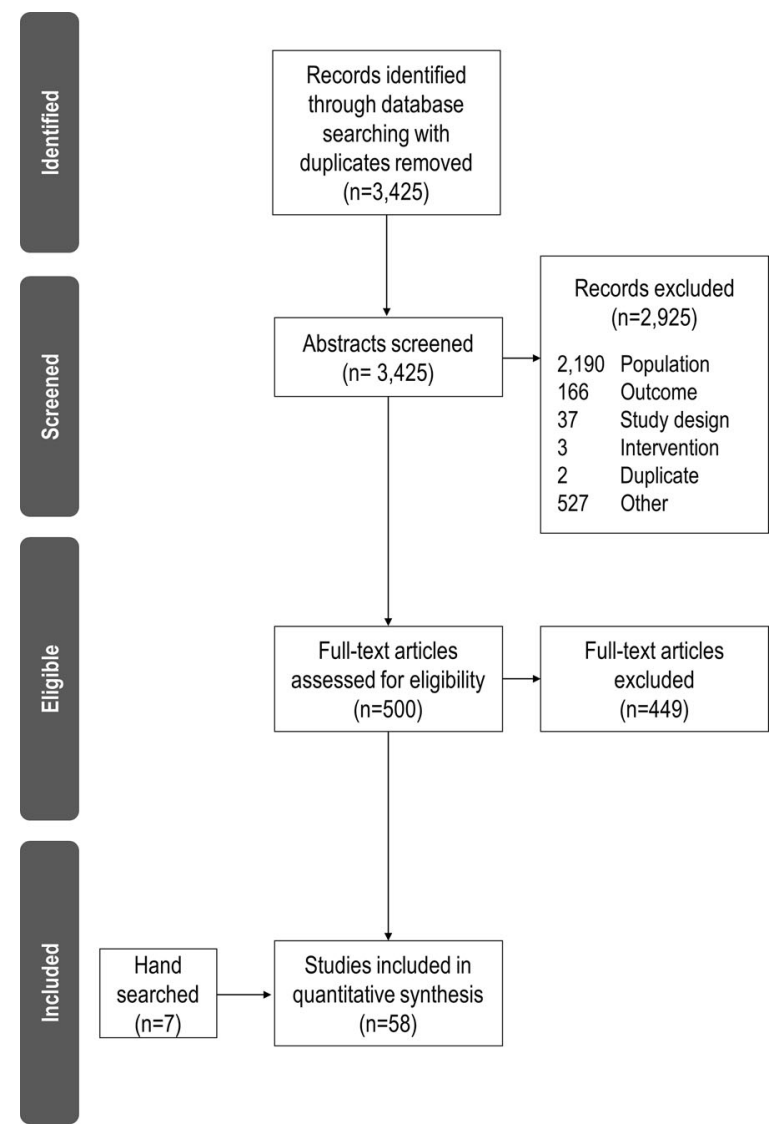

Fig. 1 PRISMA flow diagram of records identified, included and excluded hand-searching reference lists (Fig. 1). In general, the included studies were in line with the CONSORT and STROBE criteria reporting recommendations (supplementary material Tables S2-S9) [19].

\section{Study and Patient Characteristics}

All 58 studies reported results for multi-domain, OAB-specific measures with a MID available for comparison. Among these, 37 studies reported OAB-q scores (27 RCTs; three observational studies; one open-label extension; and six single-arm trials). KHQ scores were reported by 18 studies and i-QOL scores were reported by four studies (Table 1). Although the OAB-V8 (an abbreviated versions of the OAB-q) was identified in the review, it was not eligible for inclusion in the present study as it (along with the OAB-V3) is more typically used to help improve patient and physician communication regarding their symptoms, and therefore did not provide HRQoL burden over time. Similarly, the Bladder Self Assessment Questionnaire was also identified in three studies; however, as it is more often used in a lower urinary tract symptoms (LUTS) population, it did not meet the PICOS criteria $[20,21]$.

The 58 included studies consisted of 53 clinical trials and five observational [22-26] studies (Table 1). Of the clinical trials, 37 were RCTs [15, 27-62], 10 were single-arm trials [63-72] and six were open-label extension studies [73-78]. The clinical trials included eight mirabegron studies [38, 43-45, $48,58,59,61]$, six onabotulinumtoxinA studies $[30,35,49,53,54,74], 35$ antimuscarinic studies $[15,27-29,31-34,36,37,39-42$, $46,50-52,55,56,60,62-73,75,76]$, two sacral nerve modulation studies $[77,78]$, one staged InterStim procedure study [57] and one study of foot reflexology [47].

Among the 53 clinical trials, the mean number of participants per trial was 929.0 (range 106-3185), with a median length of follow-up of 12 weeks (range 3-156 weeks). Most clinical trials evaluated the impact of antimuscarinic therapies, most commonly fesoterodine (26.4\%), tolterodine (18.9\%) and solifenacin 
Table 1 Summary characteristics of included studies

\begin{tabular}{|c|c|c|c|c|}
\hline & \multicolumn{2}{|c|}{$\begin{array}{l}\text { Clinical trials } \\
N=53\end{array}$} & \multicolumn{2}{|c|}{$\begin{array}{l}\text { Observational studies } \\
N=5\end{array}$} \\
\hline \multicolumn{5}{|l|}{ Length of study (weeks) } \\
\hline Mean (SD) & 24.1 & 32.7 & 156.8 & 122.9 \\
\hline Median (range) & 12.0 & $3.0-156.0$ & 104.0 & $24.0-312.0$ \\
\hline \multicolumn{5}{|l|}{ Total number of participants } \\
\hline Mean (SD) & 929.0 & 740.3 & 292.6 & 207.6 \\
\hline Median (range) & 707.0 & $106-3185$ & 235.0 & $100.0-632.0$ \\
\hline \multicolumn{5}{|c|}{ Treatments included (number of studies, $\%)^{\mathrm{a}}$} \\
\hline Mirabegron & 5 & 9.4 & 0 & 0.0 \\
\hline Onabotulinumtoxin $\mathrm{A}$ & 6 & 11.3 & 1 & 20.0 \\
\hline Solifenacin & 10 & 18.9 & 1 & 20.0 \\
\hline Oxybutynin & 4 & 7.5 & 1 & 20.0 \\
\hline Fesoterodine & 14 & 26.4 & 0 & 0.0 \\
\hline Tolterodine & 10 & 18.9 & 1 & 20.0 \\
\hline Darifenacin & 4 & 7.5 & 1 & 20.0 \\
\hline Trospium & 4 & 7.5 & 1 & 20.0 \\
\hline Propiverine & 1 & 1.9 & 0 & 0.0 \\
\hline Mirabegron + solifenacin & 3 & 5.7 & 0 & 0.0 \\
\hline Reflexology/massage & 1 & 1.9 & 0 & 0.0 \\
\hline Detrusitol & 0 & 0.0 & 1 & 20.0 \\
\hline Sacral nerve modulation & 2 & 3.8 & 0 & 0.0 \\
\hline InterStim procedure & 1 & 1.9 & 1 & 20.0 \\
\hline Lifestyle interventions & 0 & 0.0 & 1 & 20.0 \\
\hline Placebo & 28 & 52.8 & 0 & 0.0 \\
\hline \multicolumn{5}{|c|}{ PROs included (number of studies, \%) ${ }^{\mathrm{a}}$} \\
\hline OAB-q & 34 & 64.2 & 3 & 60.0 \\
\hline PPBC & 12 & 22.6 & 0 & 0.0 \\
\hline KHQ & 18 & 34.0 & 0 & 0.0 \\
\hline IIQ-7 & 1 & 1.9 & 2 & 40.0 \\
\hline UDI-6 & 1 & 1.9 & 2 & 40.0 \\
\hline $\mathrm{i}-\mathrm{QOL}$ & 4 & 7.5 & 0 & 0.0 \\
\hline
\end{tabular}

a Some studies included multiple treatments and instruments, so percentages sum to more than $100 \%$

IIQ-7 Incontinence Impact Questionnaire, $i-Q O L$ Incontinence Specific Quality of Life, KHQ King's Health Questionnaire, $O A B-q$ Overactive Bladder Questionnaire, PPBC Patient Perception of Bladder Condition, SD standard deviation, UDI-6 Urinary Distress Inventory 
Table 2 Comparison of summary criteria for the most commonly reported overactive bladder health-related quality of life instruments

\begin{tabular}{|c|c|c|c|}
\hline & $\begin{array}{l}\text { OAB-q } \\
(n=34 \\
\text { studies })\end{array}$ & KHQ ( $n=18$ studies) & $\begin{array}{l}\text { PPBC }(n=12 \\
\text { studies })\end{array}$ \\
\hline $\begin{array}{l}\text { Comprehensively considers a wide variety of } \\
\text { OAB symptoms and bother }\end{array}$ & Yes & Yes & $\begin{array}{l}\text { No, global score } \\
\text { only }\end{array}$ \\
\hline Is specific to $\mathrm{OAB}$ & Yes & $\begin{array}{l}\text { No, developed for lower urinary } \\
\text { tract syndrome generally }\end{array}$ & Yes \\
\hline Has MID data available & Yes & Yes & Yes \\
\hline Can be used to generate a utility value & Yes & Yes & $\begin{array}{l}\text { No; algorithm } \\
\text { not available }\end{array}$ \\
\hline
\end{tabular}

All individual treatment arms within studies are included as a separate row. The overall HRQoL and symptom bother scale are included as separate columns. The four subscales (coping, concern, sleep, social) of the overall HRQoL are also included as separate columns. The range of OAB-Q score is 0-100 (where a higher symptom bother score indicates greater symptom bother, while lower HRQoL scores indicate greater impact on QOL)

$K H Q$ King's Health Questionnaire, $M I D$ minimum important difference, $O A B$ overactive bladder, $O A B-q$ Overactive Bladder Questionnaire, PPBC Patient Perception of Bladder Condition, PRISMA Preferred Reporting Items for Systematic reviews and Meta-Analyses

(18.9\%). In the clinical trials six different OABspecific measures were identified. The most frequently used PRO instruments were the OABq (34 studies; 27 RCTs, six single-arm trials and one open-label extension study), followed by the KHQ (18 studies; 14 RCTs, two single-arm trials and two open-label extension studies) and the PPBC (12 studies; nine RCTs and three open-label extension studies).

Among the five observational studies, the mean number of participants per study was 292.6 (range 100-632). These studies tended to be longer, with a median length of follow-up of 104 weeks (range 24-312 weeks). A variety of $\mathrm{OAB}$ treatments were considered, and three OAB-specific measures were used: the OAB-q (three studies), the IIQ-7 (two studies) and the UDI-6 (two studies) (Table 1).

\section{Assessment of Measures}

The most commonly administered PRO instrument was the OAB-q (64\%), followed by the KHQ (31\%) and the PPBC (21\%) (Table 1). Other instruments were included in five or fewer studies, with the i-QOL $(n=4$ studies) only used in onabotulinumtoxinA trials. How those measures performed against the assessment criteria is presented in Table 2. The OAB-q was the only instrument to meet all outlined criteria and was thus selected for more detailed synthesis. A summary of additional properties of the most commonly used PRO instruments in $\mathrm{OAB}$ studies can be found in the supplementary material Table S10.

\section{OAB-q Studies and Outcomes}

Data from 37 studies were included in the OAB$\mathrm{q}$ data synthesis. Overall, assessment of changes to OAB-q scores was reported by 22 antimuscarinic trials $[15,28,29,32-34,36,39$, $41,46,50,52,55,56,60,63,65,66,68,70,72$, 76], seven mirabegron trials $[38,43$, $44,48,58,59,61]$, two onabotulinumtoxinA trials $[53,54]$, two sacral nerve modulation trials $[77,78]$, one staged InterStim procedure study [57] and three observational studies [24-26].

Baseline OAB-q values, where reported, and change scores (final minus baseline) for symptom bother, overall HRQoL and each subscale (coping, concern, sleep, social) for individual 
studies are shown in Figs. 2 and 3, respectively. Improved HRQoL is indicated by positive change scores on individual HRQoL subscales, while for symptom bother, improvement is indicated by a negative change score from baseline.

Baseline and change score data were reported for a total of 46 and 61 study arms, respectively. Across studies, baseline HRQoL scores ranged from 35 to 68 and symptom bother scores ranged from 43 to 74 , with a majority of these (59\%) falling within a relatively small range (52 to 60 for symptom bother scores and 52 to 64 for corresponding HRQoL scores) (Fig. 2). HRQoL and symptom bother change scores (including placebo arms) ranged from 3 to 37 and from -2 to -45 , respectively. Of the 15 placebo arms reported on, all but one [55] showed a benefit relative to the MID in overall HRQoL, coping subscale, concern subscale and symptom bother scale; and 14 of the 15 placebo arms also showed a benefit for the sleep domain (Fig. 3).

Among the 22 antimuscarinic trials utilizing OAB-q, all but one reported improvement in all domains relative to the MID. The exception was in the open-label extension to a 12-week trial, for which results were measured relative to the end of the original trial $[55,76]$. The smallest numeric improvements were observed consistently in the social domain across studies. Placebo-controlled trials reported greater improvements in antimuscarinic arms relative to placebo arms. Among studies including multiple antimuscarinic doses, the study conducted by Chapple et al. reported a dose-response effect for fesoterodine [29], while the study conducted by Yamaguchi did not [56]. Notably, two other studies that included both fesoterodine and tolterodine arms did not report a notable difference in results across the two antimuscarinics $[39,60]$.

Among mirabegron clinical trials, all studies reported 12-week change scores and found improvements in all OAB-q domains relative to baseline based on MID. Improvements were observed across doses of mirabegron $(25 \mathrm{mg}$, $50 \mathrm{mg}$ and $100 \mathrm{mg}$ ). Of studies with multiple doses of mirabegron, one found a dose-response relationship [48], while the remaining two reported similar results across mirabegron doses $[38,44]$. The change scores of greatest magnitude were associated with mirabegron given in combination with solifenacin [61]. When mirabegron was given as a monotherapy in RCTs, OAB-q improvements were consistently greater for mirabegron than for placebo or antimuscarinics.

Two published studies reported OAB-q results at 26 weeks for onabotulinumtoxinA trials. Both studies were based on the same underlying trial data; one publication reported OAB-q results directly [53] while the other reported converted utility values for cost-effectiveness analysis [54]. The OAB-q results found clinically significant improvement, numerically greater than the MID, corresponding to a calculated utility improvement of approximately 0.05 .

Three observational studies reported OAB-q results. Patients received antimuscarinics in two of the studies [24, 25], and a staged InterStim procedure in the third [26]. For the most part, benefits were observed beyond the MID in at least one OAB-q domain. The exception to this was a solifenacin study, which stratified results by response status, and MID results were not achieved in the non-responder group [25].

\section{DISCUSSION}

PROs that determine the impact of interventions from the patients' perspective and quantify changes in HRQoL have become standard measures for evaluating OAB treatments. Several different instruments have been developed and validated, with optimal instrument selection guided by the study design and target patient population.

To better understand the current $\mathrm{OAB}$ research arena, a systematic literature review was undertaken to characterize the published literature reporting PROs associated with $\mathrm{OAB}$ treatment over time, identify the measures most commonly used and their alignment with specified criteria of interest. As previously reported [79], among bladder-specific instruments, the OAB-q remains the most frequently implemented PRO measure in clinical trials of 


\begin{tabular}{|c|c|c|c|c|c|c|c|}
\hline $\begin{array}{l}\text { OVERALL } \\
\text { HRQoL }\end{array}$ & Coping & Concern & Sleep & Social & $\begin{array}{l}\text { Symptom } \\
\text { Bother }\end{array}$ & & \\
\hline 41 & 37 & 34 & 38 & 63 & & - Noblett K et al. 2016 & \\
\hline 41 & 37 & 34 & 38 & 63 & & - Siegal S et al. 2016 & \\
\hline 50 & & & & & 43 & - Peters KM et al. 2013 & \\
\hline 68 & 60 & 69 & 64 & 85 & 45 & - Yamaguchi et al. 2011 & \\
\hline 67 & 59 & 67 & 62 & 83 & 47 & - Yamaguchi et al. 2011 & \\
\hline 62 & & & & & 47 & - Lee YS et al. 2011 & \\
\hline 65 & 58 & 66 & 61 & 81 & 48 & - Yamaguchi et al. 2011 & \\
\hline 65 & & & & & 48 & - Herschorn S et al. 2013 & \\
\hline 64 & & & & & 51 & - Herschorn S et al. 2013 & \\
\hline 60 & 56 & 55 & 54 & 81 & 52 & - Serels SR et al. 2010 & \\
\hline 64 & 58 & 60 & 62 & 80 & 52 & - Gotoh M et al. 2014 & \\
\hline 59 & 53 & 59 & 56 & 73 & 52 & - MacDiarmid S et al. 2016 & \\
\hline 60 & 56 & 54 & 55 & 82 & 52 & - Serels SR et al. 2010 & \\
\hline 60 & 54 & 60 & 56 & 75 & 53 & -MacDiarmid S et al. 2016 & \\
\hline 55 & & & & & 53 & - Lee KS et al. 2012 & \\
\hline 59 & 52 & 58 & 55 & 73 & 54 & -MacDiarmid S et al. 2016 & \\
\hline 61 & 57 & 56 & 53 & 82 & 55 & - Chancellor MB et al. 2008 & \\
\hline 60 & 53 & 58 & 56 & 78 & 56 & - Peeker et al. 2010 & \\
\hline 59 & 56 & 54 & 50 & 80 & 56 & - Gollar KM et al. 2012 & \\
\hline 58 & 52 & 55 & 46 & 82 & 56 & - Gollar KM et al. 2012 & \\
\hline 56 & 53 & 51 & 49 & 76 & 57 & - Garely et al. 2006 & \\
\hline 55 & 48 & 50 & 53 & 74 & 57 & - Kaplan SA et al. 2011 & Antimuscarinics \\
\hline 52 & 45 & 50 & 48 & 71 & 57 & - Coyne KS et al. 2011 & Mirabegron \\
\hline 58 & 52 & 55 & 56 & 77 & 58 & - Herschorn et al. 2010 & Procedures \\
\hline 52 & 45 & 51 & 48 & 72 & 58 & - Wyndaele et al. 2009 & Combo \\
\hline 58 & 52 & 51 & 55 & (79) & 58 & - Coyne KS et al. 2011 & Placebo \\
\hline 58 & 54 & 52 & 51 & 79 & 58 & - Vardy MD et al. 2009 & \\
\hline 56 & 52 & 52 & 47 & 79 & 58 & - Vardy MD et al. 2009 & \\
\hline 56 & 48 & 52 & 54 & 75 & 59 & - Herschorn et al. 2010 & \\
\hline 54 & 49 & 48 & (47) & 76 & 59 & - Coyne KS et al. 2011 & \\
\hline 56 & 48 & 52 & 55 & 74 & 59 & - Herschorn et al. 2010 & \\
\hline 56 & 53 & 50 & 48 & 77 & 59 & - Gollar KM et al. 2012 & \\
\hline 53 & 46 & 49 & 51 & 72 & 59 & - Kaplan SA et al. 2011 & \\
\hline 53 & 46 & 48 & 52 & 73 & 59 & - Kaplan SA et al. 2011 & \\
\hline 55 & 50 & 51 & (44) & 84 & 60 & - Roberts et al. 2006 & \\
\hline 56 & 50 & 50 & 53 & 77 & 60 & - Gollar KM et al. 2012 & \\
\hline 52 & 47 & 46 & 48 & 74 & 65 & - Dmochowski RR et al. 2010 & \\
\hline 52 & 49 & 46 & 48 & 75 & 65 & - Dmochowski RR et al. 2010 & \\
\hline 35 & & & & & 67 & - Peters KM et al. 2012 & \\
\hline 51 & 45 & 47 & 43 & 73 & 67 & - DuBeau CE et al. 2014 & \\
\hline 50 & 45 & 46 & 40 & 72 & 68 & - DuBeau CE et al. 2014 & \\
\hline 48 & 43 & 39 & 44 & 71 & 68 & -Rogers et al. 2009 & \\
\hline 47 & 40 & 42 & 44 & 67 & 69 & - Chapple C et al. 2014 & \\
\hline 45 & 38 & 41 & 44 & 64 & 69 & - Chapple C et al. 2014 & \\
\hline 44 & 37 & 40 & 42 & 65 & 70 & - Chapple C et al. 2014 & \\
\hline 38 & & & & & 74 & - Peters KM et al. 2013 & \\
\hline
\end{tabular}


४ Fig. 2 Baseline OAB-Q scores in included studies. All individual treatment arms within studies are included as a separate row. The overall HRQOL and symptom bother scale are included as separate columns. The four subscales (coping, concern, sleep, social) of the overall HRQOL are also included as separate columns. The Range of OAB-Q score is 0-100 (where a higher symptom bother score indicates greater symptom bother, while lower HRQOL scores indicate greater impact on $\mathrm{QOL}$ )

pharmacologic $\mathrm{OAB}$ therapies. OAB-q was also the only commonly reported urology instrument to comprehensively assess OAB symptoms, be specific to an $\mathrm{OAB}$ population, have a published MID and be convertible to a utility score via a published algorithm. Together, the OAB-q, KHQ and PPBC were used to measure the patients' perspectives $85 \%$ of the time, with some studies including multiple instruments. In contrast, there is no identifiable pattern of PRO instrument use among the small number of observational studies conducted to date. While measure selection in observational studies may be driven by characteristics of a population or study objectives, for ease of comparability, future randomized trials may benefit from using the OAB-q, KHQ and PPBC.

Extracted data from clinical trials using the OAB-q revealed a wide range of baseline HRQoL and symptom scores, with most participants with symptom bother scores of around 55 points, and HRQoL of around 58 points. Scores ranging from 46 to 62 on the symptom bother scale and inversely from 50 to 65 on the HRQoL subscale have previously been correlated with patients' perceiving the impact of $\mathrm{OAB}$ as moderate to severe [80]. Synthesis of data from studies using the OAB-q to monitor treatment effects revealed improvement relative to MID with placebo, in most studies, and in most domains; however, in general, where comparisons had been made, treatment-related benefits were consistently greater than placebo-related effects. The smallest change scores (with or without treatment) tended to be observed in the social domain, although all domains tended to be associated with change scores of at least the MID. Data from some of the studies including arms with interventions administered at different dosages demonstrated the OAB-q to be sufficiently sensitive to identify dose-response relationships, although this was not observed consistently across studies. The results of this synthesis could be used to characterize baseline estimates of symptom bother and HRQoL impact among patients with $\mathrm{OAB}$ and the impact of treatments on these outcomes, both of which can serve as benchmarks for future comparisons. Strengths of this study include the comprehensive and systematic approach undertaken to identify and review studies. Careful review was undertaken to ensure that data were not counted twice where individual trials are described in multiple publications and that open-label extension studies were correctly linked to the original trials. Thus, the data extracted comprise a comprehensive repository of PRO data for patients with $\mathrm{OAB}$, facilitating a broad overview as presented here, or the potential for a more focused review of specific instruments, study designs or OAB therapies. Broad study inclusion criteria encompassed observational studies and non-pharmacological clinical trials in addition to clinical trials of pharmacological treatments, although most identified studies were treatment trials. Novel data visualizations were developed to succinctly characterize baseline values and change scores for all scales and subscales of the OAB-q across multiple studies.

Limitations to the review include that numerous studies potentially of interest were excluded because of the requirement that change scores-or sufficient data to calculate change scores-for a PRO were not reported by authors. Another limitation is that the wide variety of instruments and study types included, and variation in reporting domains within instruments, presents a challenge for succinct synthesis of results. As such, the results presented here can be considered a master data set of published PRO results, from which details can be derived for more focused analyses. Finally, while several of the instruments have been validated and widely used, many instruments, including the most commonly used OAB-q, were developed prior to contemporary United States Food and Drug Administration (US FDA) guidance for PROs [81], and may not 


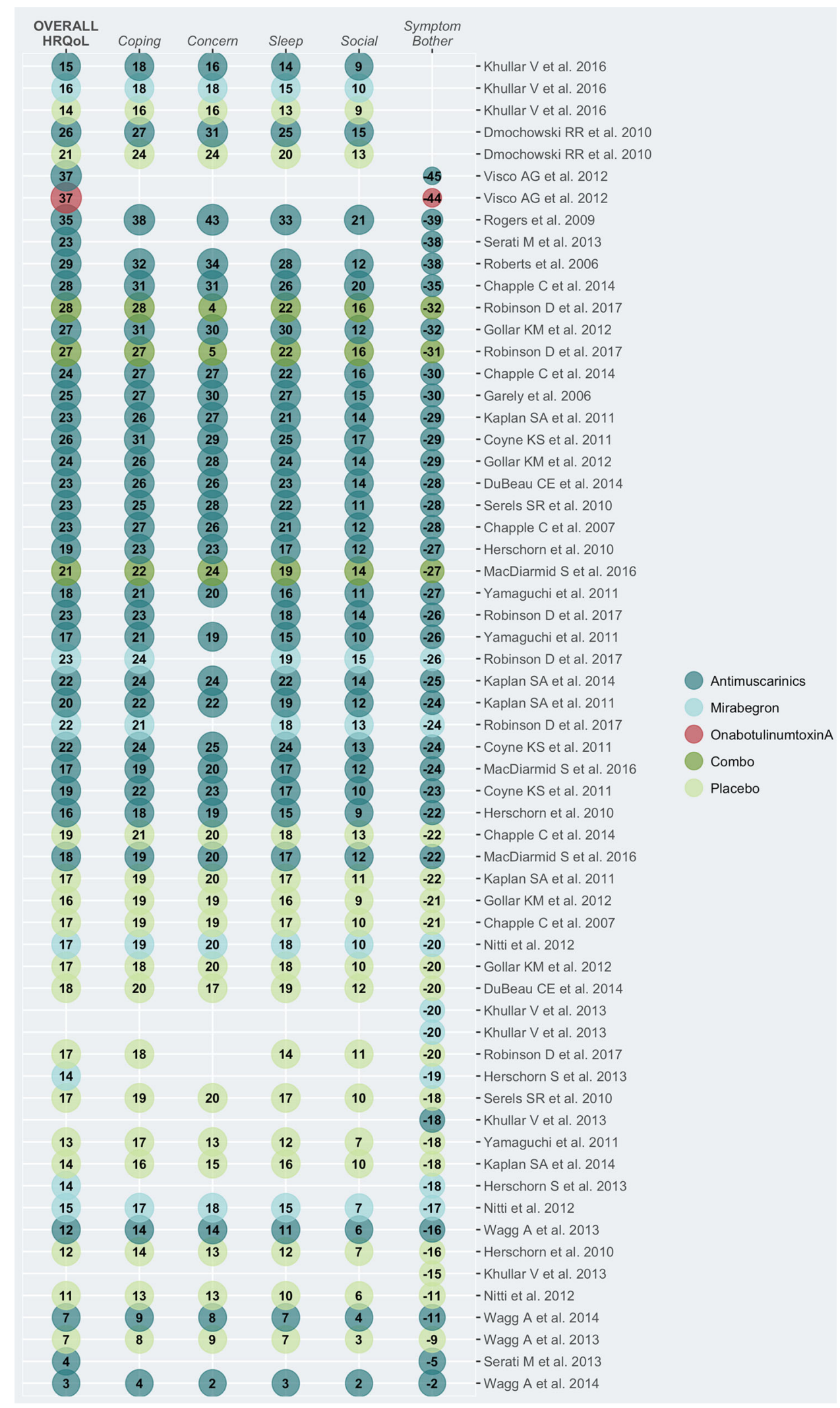


4 Fig. 3 OAB-Q change scores in included studies. All individual treatment arms within studies are included as a separate row. The overall HRQoL and symptom bother scale are included as separate columns. The four subscales (coping, concern, sleep, social) of the overall HRQoL are also included as separate columns. Range of minimum important difference $(\mathrm{MID})=10.0$ for all scales

be reflective of current best practices. Thus, while use of the OAB-q in future studies would allow for the greatest breadth of contextualization within the existing literature, its applicability is limited by lack of confirmation of development in accordance with FDA recommendations.

\section{CONCLUSION}

Clinical trials assessing the efficacy of antimuscarinics, mirabegron and onabotulinumtoxinA for the treatment of $\mathrm{OAB}$ have observed improved HRQoL. The published evidence in treatment studies indicates that improvements in the OAB-q of at least the MID are observed over time. Where comparative data were available, active treatments tended to be associated with a greater improvement than placebo, and no differences were observed across active treatments (e.g. across alternative antimuscarinic therapies, or between mirabegron and an antimuscarinic). These trends are consistent with observed data for clinical outcomes, suggesting consistency between clinical outcomes and OAB-specific PRO measures. These findings provide benchmark values for OAB-q levels across the current published literature and can inform future clinical trial development to improve consistency of data collection, making for a more robust evidence base that facilitates quantitative cross-trial comparisons of the safety and efficacy of pharmacological $O A B$ interventions.

\section{ACKNOWLEDGEMENTS}

Funding. Sponsorship for this study, article processing charges and open access were funded by Astellas Pharma Global Development Inc. All authors had full access to all of the data in this study and take complete responsibility for the integrity of the data and accuracy of the data analysis.

Editorial Assistance. We would like to thank Kath Quayle for providing editorial support in the development of this manuscript. Kath Quayle provided consultation services to Broadstreet Health Economics \& Outcomes Research (HEOR), which received payment from Astellas in the conduct of this study.

Authorship. All named authors meet the International Committee of Medical Journal Editors (ICMJE) criteria for authorship for this article, take responsibility for the integrity of the work as a whole, and have given their approval for this version to be published.

Authorship Contributions. All authors contributed to the study concept and design. KJ and PL were responsible for the acquisition of data. All authors had full access to all the data in this study and contributed to the analysis and interpretation of data. All authors contributed to the critical review and editing of the manuscript and take complete responsibility for the integrity of the data and accuracy of the data analysis.

Disclosures. David Walker is an employee of Astellas Pharma Global Development, Inc. Karissa M. Johnston is an employee of Broadstreet Health Economics and Outcomes Research (HEOR), which received funding from Astellas Pharma Global Development Inc., for the design and analysis of the data for this study. Pardis Lakzadeh is an employee of Broadstreet Health Economics and Outcomes Research (HEOR), which received funding from Astellas Pharma Global Development Inc., for the design and analysis of the data for this study.

Compliance with Ethics Guidelines. This article is based on previously conducted studies and does not contain any studies with human participants or animals performed by any of the authors. 
Data Availability. The datasets during and/ or analyzed during the current study are available from the corresponding author on reasonable request.

Open Access. This article is distributed under the terms of the Creative Commons Attribution-NonCommercial 4.0 International License (http://creativecommons.org/licenses/ by-nc/4.0/), which permits any noncommercial use, distribution, and reproduction in any medium, provided you give appropriate credit to the original author(s) and the source, provide a link to the Creative Commons license, and indicate if changes were made.

\section{REFERENCES}

1. Hashim $\mathrm{H}$, Abrams P. Overactive bladder: an update. Curr Opin Urol. 2007;17(4):231-6.

2. Coyne KS, Sexton CC, Vats V, Thompson C, Kopp ZS, Milsom I. National community prevalence of overactive bladder in the United States stratified by sex and age. Urology. 2011;77(5):1081-7.

3. Milsom I, Coyne KS, Nicholson S, Kvasz M, Chen CI, Wein AJ. Global prevalence and economic burden of urgency urinary incontinence: a systematic review. Eur Urol. 2014;65(1):79-95.

4. Irwin DE, Milsom I, Hunskaar S, Reilly K, Kopp Z, Herschorn $S$, et al. Population-based survey of urinary incontinence, overactive bladder, and other lower urinary tract symptoms in five countries: results of the EPIC study. Eur Urol. 2006;50(6):1306-14 (discussion 14-5).

5. Irwin DE, Milsom I, Kopp Z, Abrams P. Symptom bother and health care-seeking behavior among individuals with overactive bladder. Eur Urol. 2008;53(5):1029-39.

6. Milsom I, Abrams P, Cardozo L, Roberts RG, Thuroff $\mathrm{J}$, Wein AJ. How widespread are the symptoms of an overactive bladder and how are they managed? A population-based prevalence study. BJU Int. 2001;87(9):760-6.

7. Stewart W, Van Rooyen J, Cundiff G, et al. Prevalence and burden of overactive bladder in the United States. World J Urol. 2003;20(6):327-36.

8. Wagner TH, Hu TW, Bentkover J, et al. Health-related consequences of overactive bladder. Am J Manag Care. 2002;8(19 Suppl):S598-607.
9. Brazier J, Czoski-Murray C, Roberts J, Brown M, Symonds T, Kelleher C. Estimation of a preferencebased index from a condition-specific measure: the King's health Questionnaire. Med Decis Making. 2008;28(1):113-26.

10. Yang Y, Brazier J, Tsuchiya A, Coyne K. Estimating a preference-based single index from the Overactive Bladder Questionnaire. Value Health. 2009;12(1):159-66.

11. Wein AJ. How much is enough and who says so? The case of the King's Health Questionnaire and overactive bladder. J Urol. 2005;173(3):908.

12. Wiklund I. Assessment of patient-reported outcomes in clinical trials: the example of health-related quality of life. Fundam Clin Pharmacol. 2004;18(3):351-63.

13. Basra R, Kelleher C. Disease burden of overactive bladder: quality-of-life data assessed using ICI-recommended instruments. Pharmacoeconomics. 2007;25(2):129-42.

14. Dyer $\mathrm{KY}, \mathrm{Xu} \mathrm{Y}$, Brubaker $\mathrm{L}$, et al. Minimum important difference for validated instruments in women with urge incontinence. Neurourol Urodyn. 2011;30(7):1319-24.

15. Serels SR, Toglia MR, Forero-Schwanhaeuser S, He $\mathrm{W}$. Impact of solifenacin on diary-recorded and patient-reported urgency in patients with severe overactive bladder $(\mathrm{OAB})$ symptoms. Curr Med Res Opin. 2010;26(10):2277-85.

16. Moher D, Hopewell S, Schulz KF, et al. CONSORT 2010 explanation and elaboration: updated guidelines for reporting parallel group randomised trials. Int J Surg. 2012;10(1):28-55.

17. Vandenbroucke JP, von Elm E, Altman DG, et al. Strengthening the Reporting of Observational Studies in Epidemiology (STROBE): explanation and elaboration. Int J Surg. 2014;12(12):150024.

18. Sacco E, Tienforti D, D'Addessi A, et al. Social, economic, and health utility considerations in the treatment of overactive bladder. Open Access J Urol. 2010;2:11-24.

19. PLOS Medicine Editors. Observational studies: getting clear about transparency. PLoS Med. 2014;11(8):e1001711.

20. Basra R, Artibani W, Cardozo L, et al. Design and validation of a new screening instrument for lower urinary tract dysfunction: the bladder control selfassessment questionnaire (B-SAQ). Eur Urol. 2007;52(1):230-7. 
21. Sahai A, Dowson C, Cortes E, et al. Validation of the bladder control self-assessment questionnaire (BSAQ) in men. BJU Int. 2014;113(5):783-8.

22. Dowson C, Watkins J, Khan MS, Dasgupta P, Sahai A. Repeated botulinum toxin type A injections for refractory overactive bladder: medium-term outcomes, safety profile, and discontinuation rates. Eur Urol. 2012;61(4):834-9.

23. Esin E, Ergen A, Cankurtaran M, et al. Influence of antimuscarinic therapy on cognitive functions and quality of life in geriatric patients treated for overactive bladder. Aging Ment Health. 2015;19(3): 217-23.

24. Peeker R, Samsioe G, Kowalski J, Andersson AS, Bergqvist A. A prospective observational study of the effects of treatment with extended-release tolterodine on health-related quality of life of patients suffering overactive bladder syndrome in Sweden. Scand J Urol Nephrol. 2010;44(3):138-46.

25. Serati M, Braga A, Siesto G, et al. Risk factors for the failure of antimuscarinic treatment with solifenacin in women with overactive bladder. Urology. 2013;82(5):1044-8.

26. Peters KM, Killinger KA, Gilleran J, Boura JA. Does patient age impact outcomes of neuromodulation? Neurourol Urodyn. 2013;32(1):30-6.

27. Abrams P, Kelleher C, Huels J, Quebe-Fehling E, Omar MA, Steel M. Clinical relevance of health-related quality of life outcomes with darifenacin. BJU Int. 2008;102(2):208-13.

28. Chapple C, DuBeau C, Ebinger U, Rekeda L, Viegas A. Darifenacin treatment of patients $>$ or $=65$ years with overactive bladder: results of a randomized, controlled, 12-week trial. Curr Med Res Opin. 2007;23(10):2347-58.

29. Chapple C, Schneider T, Haab F, et al. Superiority of fesoterodine $8 \mathrm{mg}$ vs $4 \mathrm{mg}$ in reducing urgency urinary incontinence episodes in patients with overactive bladder: results of the randomised, double-blind, placebo-controlled EIGHT trial. BJU Int. 2014;114(3):418-26.

30. Chapple C, Sievert KD, MacDiarmid S, et al. OnabotulinumtoxinA 100 U significantly improves all idiopathic overactive bladder symptoms and quality of life in patients with overactive bladder and urinary incontinence: a randomised, doubleblind, placebo-controlled trial. Eur Urol. 2013;64(2):249-56.

31. Chapple CR, Van Kerrebroeck PE, Junemann KP, Wang JT, Brodsky M. Comparison of fesoterodine and tolterodine in patients with overactive bladder. BJU Int. 2008;102(9):1128-32.
32. Coyne KS, Gelhorn H, Thompson C, Kopp ZS, Guan $\mathrm{Z}$. The psychometric validation of a 1-week recall period for the OAB-q. Int Urogynecol J. 2011; 22(12):1555-63.

33. Dmochowski RR, Rosenberg MT, Zinner NR, Staskin DR, Sand PK. Extended-release trospium chloride improves quality of life in overactive bladder. Value Health. 2010;13(2):251-7.

34. Dubeau CE, Kraus SR, Griebling TL, et al. Effect of fesoterodine in vulnerable elderly subjects with urgency incontinence: a double-blind, placebo controlled trial. J Urol. 2014;191(2):395-404.

35. Fowler CJ, Auerbach S, Ginsberg D, et al. OnabotulinumtoxinA improves health-related quality of life in patients with urinary incontinence due to idiopathic overactive bladder: a 36-week, doubleblind, placebo-controlled, randomized, dose-ranging trial. Eur Urol. 2012;62(1):148-57.

36. Gollar KM, Young DG, Bailen J, He W, ForeroSchwanhaeuser S. Efficacy of solifenacin for overactive bladder symptoms, symptom bother, and health-related quality of life in patients by duration of self-reported symptoms: a secondary analysis of the VIBRANT study. Urol Nurs. 2012;32(1): $38-46$.

37. Gotoh M, Yokoyama O, Nishizawa O, Japanese Propiverine Study Group. Propiverine hydrochloride in Japanese patients with overactive bladder: a randomized, double-blind, placebo-controlled trial. Int J Urol. 2011;18(5):365-73.

38. Herschorn S, Barkin J, Castro-Diaz D, et al. A phase III, randomized, double-blind, parallel-group, placebo-controlled, multicentre study to assess the efficacy and safety of the beta3 adrenoceptor agonist, mirabegron, in patients with symptoms of overactive bladder. Urology. 2013;82(6):1457 (Erratum appears in Urology).

39. Herschorn S, Swift S, Guan Z, et al. Comparison of fesoterodine and tolterodine extended release for the treatment of overactive bladder: a head-to-head placebo-controlled trial. BJU Int. 2010;105(1): 58-66.

40. Homma Y, Koyama N. Minimal clinically important change in urinary incontinence detected by a quality of life assessment tool in overactive bladder syndrome with urge incontinence. Neurourol Urodyn. 2006;25(3):228-35.

41. Kaplan SA, Schneider T, Foote JE, Guan Z, Carlsson M, Gong J. Superior efficacy of fesoterodine over tolterodine extended release with rapid onset: a prospective, head-to-head, placebo-controlled trial. BJU Int. 2011;107(9):1432-40. 
42. Kelleher CJ, Tubaro A, Wang JT, Kopp Z. Impact of fesoterodine on quality of life: pooled data from two randomized trials. BJU Int. 2008;102(1):56-61.

43. Khullar V, Amarenco G, Angulo JC, et al. Patientreported outcomes with the $\beta_{3}$-adrenoceptor agonist mirabegron in a phase III trial in patients with overactive bladder. Neurourol Urodyn. 2016;35(8): 987-94.

44. Khullar V, Amarenco G, Angulo JC, et al. Efficacy and tolerability of mirabegron, a beta(3)-adrenoceptor agonist, in patients with overactive bladder: results from a randomised European-Australian phase 3 trial. Eur Urol. 2013;63(2):283-95.

45. Kuo HC, Lee KS, Na Y, et al. Results of a randomized, double-blind, parallel-group, placebo- and active-controlled, multicenter study of mirabegron, a beta3-adrenoceptor agonist, in patients with overactive bladder in Asia. Neurourol Urodyn. 2015;34(7):685-92.

46. Lee YS, Choo MS, Lee JY, Oh SJ, Lee KS. Symptom change after discontinuation of successful antimuscarinic treatment in patients with overactive bladder symptoms: a randomised, multicentre trial. Int J Clin Pract. 2011;65(9):997-1004.

47. Mak HL, Cheon WC, Wong T, Liu YS, Tong WM. Randomized controlled trial of foot reflexology for patients with symptomatic idiopathic detrusor overactivity. Int Urogynecol J Pelvic Floor Dysfunct. $2007 ; 18(6): 653-8$.

48. Nitti VW, Auerbach S, Martin N, Calhoun A, Lee M, Herschorn S. Results of a randomized phase III trial of mirabegron in patients with overactive bladder. J Urol. 2013;189(4):1388-95.

49. Nitti VW, Dmochowski R, Herschorn S, et al. OnabotulinumtoxinA for the treatment of patients with overactive bladder and urinary incontinence: results of a phase 3 , randomized, placebo controlled trial. J Urol. 2013;189(6):2186-93.

50. Rogers RG, Omotosho T, Bachmann G, Sun F, Morrow JD. Continued symptom improvement in sexually active women with overactive bladder and urgency urinary incontinence treated with tolterodine ER for 6 months. Int Urogynecol J Pelvic Floor Dysfunct. 2009;20(4):381-5.

51. Sand PK, Davila GW, Lucente VR, Thomas H, Caramelli KE, Hoel G. Efficacy and safety of oxybutynin chloride topical gel for women with overactive bladder syndrome. Am J Obstet Gynecol. 2012;206(2):168 e1-6.

52. Vardy MD, Mitcheson HD, Samuels TA, et al. Effects of solifenacin on overactive bladder symptoms, symptom bother and other patient-reported outcomes: results from VIBRANT—a double-blind, placebo-controlled trial. Int J Clin Pract. 2009; 63(12):1702-14.

53. Visco AG, Brubaker L, Richter HE, et al. Anticholinergic therapy vs. onabotulinumtoxinA for urgency urinary incontinence. $\mathrm{N}$ Engl J Med. 2012;367(19):1803-13.

54. Visco AG, Zyczynski H, Brubaker L, et al. Cost-effectiveness analysis of anticholinergics versus botox for urgency urinary incontinence: results from the anticholinergic versus botox comparison randomized trial. Female Pelvic Med Reconstr Surg. 2016;22(5):311-6.

55. Wagg A, Khullar V, Marschall-Kehrel D, et al. Flexible-dose fesoterodine in elderly adults with overactive bladder: results of the randomized, doubleblind, placebo-controlled study of fesoterodine in an aging population trial. J Am Geriatr Soc. 2013;61(2):185-93.

56. Yamaguchi O, Nishizawa O, Takeda M, et al. Efficacy, safety and tolerability of fesoterodine in asian patients with overactive bladder. Low Urin Tract Symptoms. 2011;3(1):43-50.

57. Peters K, Carrico D, MacDiarmid S, Wooldridge L. Insight into percutaneous tibial nerve stimulation: critical evaluation of the SUMIT trial. J Urol. 2011;185(4s):e465. https://doi.org/10.1016/j.juro. 2011.02.769.

58. Robinson D, Kelleher C, Staskin D, et al. Patientreported outcomes from SYNERGY, a randomized, double-blind, multicenter study evaluating combinations of mirabegron and solifenacin compared with monotherapy and placebo in $\mathrm{OAB}$ patients. Neurourol Urodyn. 2018;37(1):394-406.

59. Abrams P, Kelleher C, Staskin D, et al. Combination treatment with mirabegron and solifenacin in patients with overactive bladder: exploratory responder analyses of efficacy and evaluation of patient-reported outcomes from a randomized, double-blind, factorial, dose-ranging, phase II study (SYMPHONY). World J Urol. 2017;35(5):827-38.

60. Kaplan SA, Cardozo L, Herschorn S, et al. Efficacy and safety of fesoterodine $8 \mathrm{mg}$ in subjects with overactive bladder after a suboptimal response to tolterodine ER. Int J Clin Pract. 2014;68(9): 1065-73.

61. MacDiarmid S, Al-Shukri S, Barkin J, et al. Mirabegron as add-on treatment to solifenacin in patients with incontinent overactive bladder and an inadequate response to solifenacin monotherapy. J Urol. 2016;196(3):809-18. 
62. Van Kerrebroeck PE, Kelleher CJ, Coyne KS, Kopp Z, Brodsky M, Wang JT. Correlations among improvements in urgency urinary incontinence, health-related quality of life, and perception of bladder-related problems in incontinent subjects with overactive bladder treated with tolterodine or placebo. Health Qual Life Outcomes. 2009;7:13.

63. Chancellor MB, Zinner N, Whitmore K, et al. Efficacy of solifenacin in patients previously treated with tolterodine extended release $4 \mathrm{mg}$ : results of a 12-week, multicenter, open-label, flexible-dose study. Clin Ther. 2008;30(10):1766-81.

64. Chu CM, Harvie HS, Smith AL, Arya LA, Andy UU. The impact of treatment of overactive bladder on physical activity limitations. J Womens Health (Larchmt). 2016;25(8):801-5.

65. Garely AD, Kaufman JM, Sand PK, Smith N, Andoh M. Symptom bother and health-related quality of life outcomes following solifenacin treatment for overactive bladder: the VESIcare Open-Label Trial (VOLT). Clin Ther. 2006;28(11):1935-46.

66. Gotoh M, Kobayashi T, Sogabe K. Impact of symptom improvement on patients' bother and quality of life in female patients with overactive bladder treated by solifenacin (SET-Q). Int $\mathrm{J}$ Urol. 2014;21(5):505-11.

67. Khullar V, Cardozo L, Kelleher CJ, et al. Effects of drug cessation after flexible-dose fesoterodine in patients with overactive bladder. BJU Int. 2013;112(6):820-9.

68. Lee KS, Lee YS, Kim JC, Seo JT, Lee JZ, Choo MS. Patient-reported goal achievement after antimuscarinic treatment in patients with overactive bladder symptoms. Int J Clin Pract. 2012;66(7):663-70.

69. Liu M, Wang J, Yang Y, et al. Overactive bladder symptom score to evaluate efficacy of solifenacin for the treatment of overactive bladder symptoms. Chin Med J (Engl). 2014;127(2):261-5.

70. Roberts R, Bavendam T, Glasser DB, Carlsson M, Eyland N, Elinoff V. Tolterodine extended release improves patient-reported outcomes in overactive bladder: results from the IMPACT trial. Int J Clin Pract. 2006;60(6):752-8.

71. Sand P, Zinner N, Newman D, et al. Oxybutynin transdermal system improves the quality of life in adults with overactive bladder: a multicentre, community-based, randomized study. BJU Int. 2007;99(4):836-44.
72. Wyndaele JJ, Goldfischer ER, Morrow JD, et al. Effects of flexible-dose fesoterodine on overactive bladder symptoms and treatment satisfaction: an open-label study. Int J Clin Pract. 2009;63(4):560-7.

73. Dwyer P, Kelleher C, Young J, et al. Long-term benefits of darifenacin treatment for patient quality of life: results from a 2-year extension study. Neurourol Urodyn. 2008;27(6):540-7.

74. Nitti VW, Ginsberg D, Sievert KD, et al. Durable efficacy and safety of long-term onabotulinumtoxinA treatment in patients with overactive bladder syndrome: final results of a 3.5-year study. J Urol. 2016;196(3):791-800.

75. Van Kerrebroeck PE, Heesakkers J, Berriman S, Padmanabhan Aiyer L, Carlsson M, Guan Z. Longterm safety, tolerability and efficacy of fesoterodine treatment in subjects with overactive bladder symptoms. Int J Clin Pract. 2010;64(5):584-93.

76. Wagg A, Khullar V, Michel MC, Oelke M, Darekar A, Bitoun CE. Long-term safety, tolerability and efficacy of flexible-dose fesoterodine in elderly patients with overactive bladder: open-label extension of the SOFIA trial. Neurourol Urodyn. 2014;33(1):106-14.

77. Siegel S, Noblett K, Mangel J, et al. Three-year follow-up results of a prospective, multicenter study in overactive bladder subjects treated with sacral neuromodulation. Urology. 2016;94:57-63.

78. Noblett K, Siegel S, Mangel J, et al. Results of a prospective, multicenter study evaluating quality of life, safety, and efficacy of sacral neuromodulation at twelve months in subjects with symptoms of overactive bladder. Neurourol Urodyn. 2016;35(2):246-51.

79. Coyne KS, Tubaro A, Brubaker L, Bavendam T. Development and validation of patient-reported outcomes measures for overactive bladder: a review of concepts. Urology. 2006;68(2):9-16.

80. Coyne KS, Matza LS, Kopp Z, Abrams P. The validation of the patient perception of bladder condition (PPBC): a single-item global measure for patients with overactive bladder. Eur Urol. 2006;49(6):1079-86.

81. US Food and Drug Administration. Guidance for Industry. Patient-reported outcome measures: use in medical product development to support labeling claims. https://www.fda.gov/downloads/drugs/ guidances/ucm193282.pdf. 2009. 